INTERNATIONAL DESIGN CONFERENCE - DESIGN 2018

https://doi.org/10.21278/idc.2018.0180

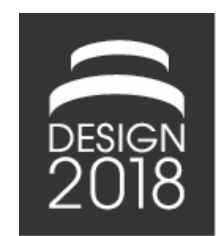

\title{
WHAT DESIGN PRACTICES DO PROFESSIONALS USE FOR SUSTAINABILITY AND INNOVATION?
}

\author{
J. Faludi and A. M. Agogino
}

\begin{abstract}
Interviews with 27 professionals were performed to investigate what designers, engineers, and their managers value in sustainable design practices, and see how sustainable design practices might also provide innovation. Quantitative and qualitative analysis found that only 1/6th of design practices were valued for both sustainability and innovation; two often-mentioned practices were systems thinking and The Natural Step. Providing a new lens, broadening scope, and problem redefinition were some of the reasons these and other design practices were valued for both sustainability and innovation.
\end{abstract}

Keywords: sustainable design, design methods, eco-innovation, ecodesign

\section{Introduction}

This paper presents the results of 27 interviews of designers, engineers, and managers in consultancies, manufacturing firms, and universities, concerning what design practices they value for innovation and sustainability. Having sustainable design practices also drive innovation may spur broader adoption in industry, because as others have found, "an ecodesign improvement option only stands a chance if it is supported by stimuli other than the expected environmental benefit alone" (Van Hemel and Cramer, 2002). Many have shown that sustainable design can drive business benefits such as cost savings, liability reduction, and marketing value (Papanek, 1995; Hawken et al., 2013; Epstein and Buhovac, 2014; Lozano, 2015; Ceschin and Gaziulusoy, 2016). Some have studied how sustainability in general (not specific practices) can drive innovation in industry (Porter and Kramer, 2011; Santolaria et al., 2011; Aronson, 2013). For specific sustainable design practices, some have classified practices by what their value should be theoretically (Oehlberg et al., 2012; Rossi et al., 2016; Telenko et al., 2016). A few have explored what specific sustainable design practices are actually valued in industry and why, but they tend to be limited to single companies (Van Hemel and Cramer, 2002; Lindahl, 2006) and/or case studies of single design practices (Kobayashi, 2006; Ameli et al., 2017). There is a gap in the research on the overlap between specific sustainable design practices and innovation with a broad set of industry participants. There is also a research gap around what "traditional" design practices are used alongside sustainable design practices, which should be understood to synergize or at least accommodate them. Thus, this study interviewed industry practitioners from multiple companies and industry sectors to answer the following research questions: What traditional and sustainable design practices do professional design practitioners actually use in their daily work for innovation, sustainability, or both? Why are these design practices valued? Understanding these will support recommendation or creation of sustainable design methods that also drive innovation.

\section{Methods}

This section presents the research approach, listing participant demographics, interview questions, and how the data was analyzed. 


\subsection{Participant demographics}

Participants were 27 professionals, purposefully sampled to represent a broad range of the profession, especially large manufacturers and small design consultancies, as these were assumed to have the largest difference in needs / workflow; gender balance, geographic diversity, and a broad range of industries were also sought out. See Figure 1. While 27 is a small sample size, others have shown interviews of ten to twenty people can be sufficient to capture preferences of a target audience (Griffin and Hauser, 1993). Participant job roles were 59\% designer, 59\% engineer, $44 \%$ manager / executive, and $41 \%$ sustainability specialist (though $59 \%$ had sustainable design experience). Demographic divisions here and elsewhere often total over $100 \%$ due to people performing multiple roles, sometimes for multiple organizations. Participants were $41 \%$ female, $59 \%$ male; $74 \%$ worked for large companies (over 100 employees), 44\% for small companies (under 100 employees); 67\% worked for consultancies, $22 \%$ for manufacturers, $22 \%$ taught in universities but formerly worked for manufacturers. They were located in nine countries (Australia, Brazil, Finland, Germany, Mexico, Netherlands, New Zealand, Sweden) and seven US states (California, Michigan, Minnesota, New York, Ohio, Pennsylvania, Wisconsin).

Figure 1 shows that most manufacturers were large, while most consultancies were small. Industries included six consumer electronics specialists, four furniture specialists, eleven generalists working in many product categories, and eleven specialists in other categories such as apparel, aerospace, automotive, packaging, and telecom.

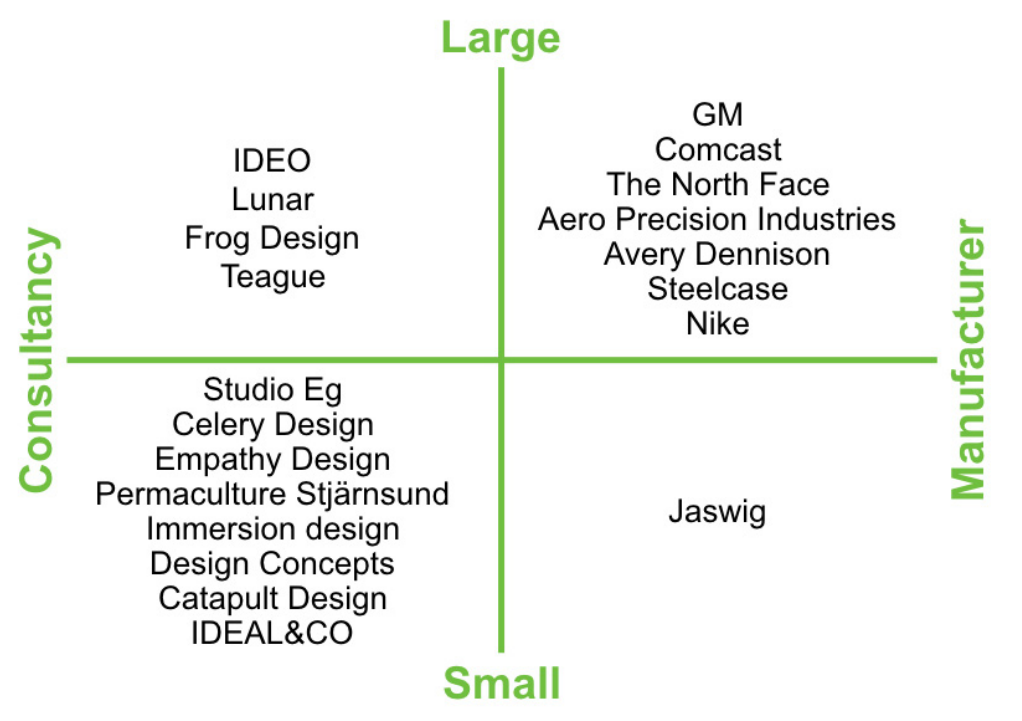

Figure 1. Interviewee companies, sorted by company type (product development consultancy or manufacturer) and size ("small" below 100 employees, "large" above 100); an additional six individual consultants are not shown, to retain anonymity

Reliability and generalizability of the 27 interviews were checked against 183 written surveys performed afterwards with different participants, part of a larger study offering workshops on sustainable design methods. The different population was for generalizability, but for reliability it was purposefully sampled to represent a similarly broad set of job roles, industries, and company types. Participants comprised $31 \%$ designers, $30 \%$ engineers, $22 \%$ managers / executives, $10 \%$ sustainability specialists, and $15 \%$ left job role blank; $52 \%$ were manufacturers, $34 \%$ product development consultancy, $14 \%$ left blank; $40 \%$ specialized in consumer electronics, $21 \%$ apparel, $20 \%$ furniture, $9 \%$ housewares / other, $15 \%$ blank; $35 \%$ were female, $48 \%$ male, $17 \%$ blank. Three companies were acquired by "snowballing". 


\subsection{Data collection}

Most interviews lasted $45-60$ minutes, though two were 90 minutes and three were opportunistic tenminute interviews at a conference; most interviews were conducted by phone or Skype, but five were conducted in person, and seven occurred by email, due to schedule logistics. Full-text transcripts were used wherever possible, but for the in-person interviews, only written notes were used, due to participants wishing not to be recorded or due to poor recording conditions. The results of these different interview methods were compared to the fifteen interviews performed in exactly the same manner, and they were consistent both qualitatively and quantitatively (though small sample sizes prevented statistical significance). The irregular interviews were deemed worth including because they broadened the number of companies involved and some of their quotes helped illustrate points well. Interviews were semi-structured, with universal questions followed up for details; question order was generally consistent but sometimes altered to adjust to conversational follow-up. This study was part of a larger project, so interviews included questions outside the scope of this paper as well. Questions relevant to this study were:

- What design processes or methods do you usually use? What would you say are the activities / mindsets used in them?

- What do you value in those activities or mindsets?

- How do those drive innovation?

- Do you regularly practice sustainable design?

- What green design method or tools do you use? Why?

- How do those drive environmental improvements?

For the written surveys of the other population, the one relevant question was: "In your practice, what design methods, activities, or mindsets do you get the most value from? Why?"

\subsection{Analysis}

Interview transcripts and surveys were analysed by qualitatively coding each specific design practice mentioned, whether each was sustainability-related, innovation-related, other business benefit-related, valued or criticized, and reasons why. Initial "open coding" of practices and reasons for value or criticism were clustered into code categories for final coding. For example, the interview text "Design Guides tend to have two effects, at least ones that I've observed. One is that it helps people pull out of their shell if they've forgotten to think about something, it allows them to think about it and explore it a little deeper" was tagged with three codes: "Design Guide", "valued", and "reason - focus / clarify thought". The text "I would say the four system conditions were the most useful, because they give me a specific frame or lens through which to look that I would not necessarily have looked through before. So I think that was the most useful part from a sustainability point of view" was coded "sustainabilityrelated", "Four System Conditions", "valued", and "reason - new lens".

MaxQDA software was used to count occurrences and co-occurrences (overlaps) of these codes in text. Each was counted only once per interview or survey, to avoid vocal minorities. The lead author coded all interviews and surveys and determined coding rubrics, then four research assistants were trained in the rubrics using the three shortest interviews and one average-length interview, then five average surveys; the 23 other interviews and 178 other surveys were coded by both the primary investigator and one research assistant each. One more round of negotiation was used to align coding rubrics between all coders, resulting in an intercoder reliability Cohen's Kappa of .82 for interviews and .84 for surveys. After all interviews were analysed, they were divided into demographic subgroups to determine if different populations held different values. The demographics tested were job role (designer / engineer / manager / sustainability specialist), company type (consultancy / product manufacturer), company size (large / small), gender (female / male), and industry (consumer electronics / furniture / apparel / other).

Reliability and generalizability of the 27 interviews were checked against the 183 written surveys by comparing frequently mentioned design practices in each, quantitatively and qualitatively. This was divided into traditional and sustainable design practices, and divided into mentions of sustainability or innovation value. 


\section{Results}

Interview results are listed here first quantitatively (counting how many people mentioned using design practices, and whether they valued them for innovation or sustainability or both), then qualitatively (why they valued or criticized each design practice). While differences by demographic did appear, such as sustainability experts valuing green design practices more often, no demographic differences were statistically significant, due to small sample size.

\subsection{Often-valued design practices}

Figure 2 counts the number of people mentioning each design practice as something they use or value, something sustainability-related, innovation-related, or criticized. While general trends do appear, there can be no statistically significant claims to what design practices are valued most, due to small sample size. Practices that were only mentioned by one person are collectively counted as "other practice" or "other brainstorm / ideation" if they were ideation techniques. "Green goals / strategies" includes energy efficiency, reduction of material use, green material choice, and other sustainability-related goals independent of design activities. "Design guide" counted any design guide (Living Principles, Designer's Field Guide to Sustainability by Lunar, Okala, and others); note that often-mentioned design guides also appear separately in the figure. "Backcasting (TNS)" and "3 prioritizing questions (TNS)" are both parts of The Natural Step. "Drawing system map (WSM)" is part of Whole System Mapping. "D4S" is TU Delft's Design for Sustainability process (Crul and Diehl, 2006).

Figure 2 shows that few design practices were valued for both sustainability and innovation. The majority were valued primarily for sustainability (defined as more than one-third of mentions being sustainability-related but not innovation-related). This is partly due to the high percentage of sustainable design experts participating and the framing of the interviews being a study on sustainable design practices, but it is also due to traditional designers mentioning a multitude of specific design practices that were only mentioned by one or two people and thus listed as "other practice" or "other brainstorm / ideation"). A relatively small percent of design practices, roughly $1 / 6^{\text {th }}$, were valued primarily for innovation (more than one-third of mentions were innovation-related, but fewer than one-third were sustainability-related). This was due largely to a difference of opinions on the definition of innovation, where some interviewees defined innovation as novelty, not including improved quality ("good" design). Interviewees were almost universally more concerned with "good" design than novel design, even those who defined innovation to include quality. Finally, roughly $1 / 6^{\text {th }}$ of design practices were valued for both innovation and sustainability (with more than one-third of mentions for both). These results do not carry statistical significance, but helped inform the qualitative research below.

As Figure 2 shows, the design practices valued for both sustainability and innovation were Systems Thinking, The Natural Step, Research, Analogy, Company Culture, Whole System Mapping, and Natural Capitalism / Factor Ten Engineering. The Cradle to Cradle book and Biomimicry were also mentioned multiple times as innovation-related; they only failed to reach the one-third cutoff because they were mentioned so often for sustainability. Interestingly, some design practices were mentioned as sustainability-related more often than they were mentioned as valued (LCA, Biomimicry, the Cradle to Cradle book, Design Guides, The Natural Step, and Laws / Regulations); this was due to criticism. This did not occur with any innovation-related design practices. Perhaps driving innovation is always valued, or the design practices to drive it are stronger due to greater use; such questions are outside the scope of this study. Note that some of the most frequently-valued design practices are also the most frequently criticized. 


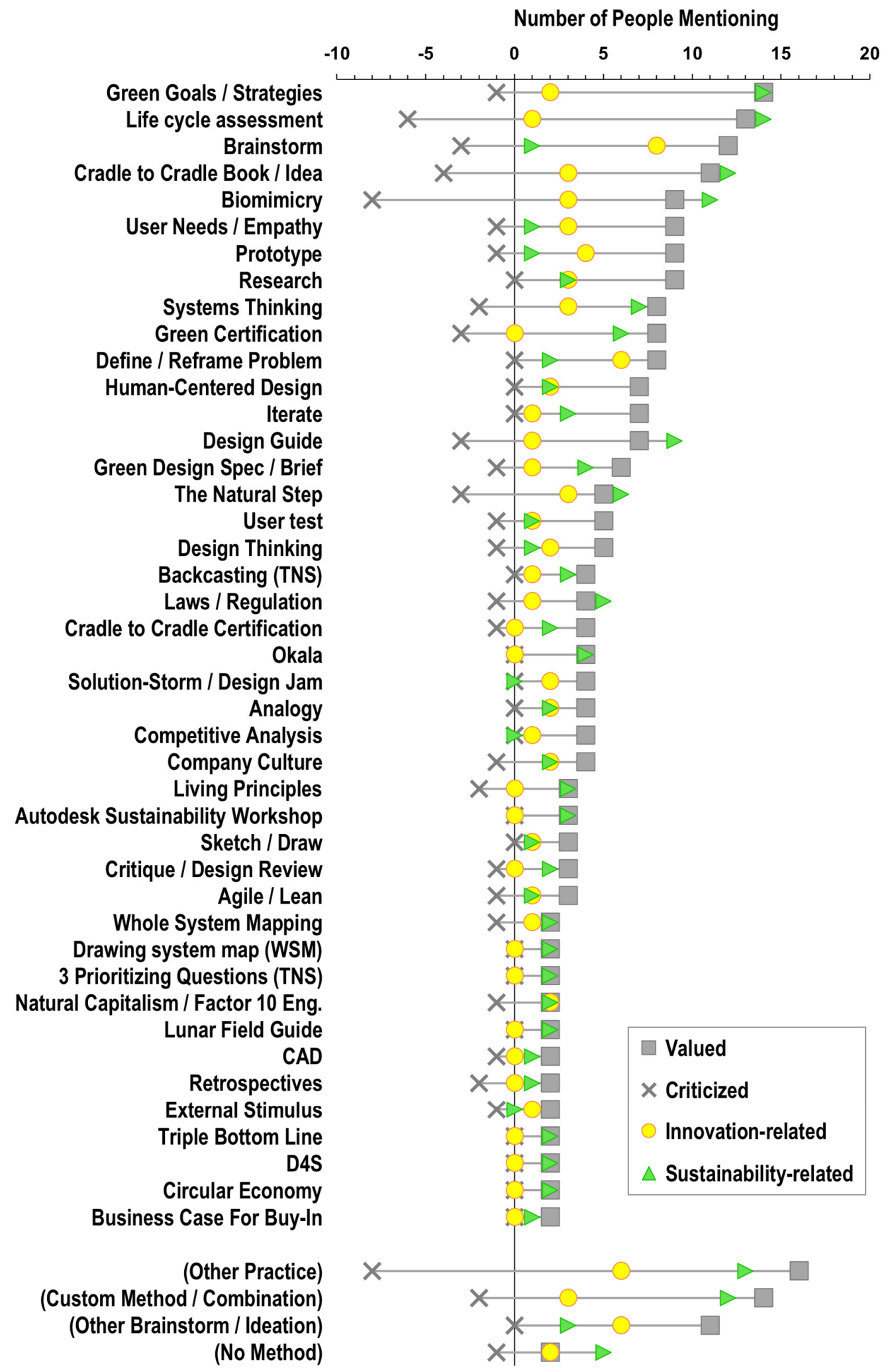

Figure 2. Frequency of interviewees $(n=27)$ mentioning design practices they value or criticize, and whether they were mentioned as sustainability-related or innovation-related 


\subsection{Why specific design practices are valued}

Qualitatively, interviewees valued often-mentioned design practices for the reasons presented below, when reasons were mentioned. Table 1 lists traditional design practices and Table 2 lists sustainable design practices. Almost all design practices, both traditional and sustainability-related, were valued for their results (better products or ideas). Because of this ubiquity, "results" are not listed in the tables below, except for brainstorming, where interviewees specifically mentioned different kinds of results: quantity, novelty, and quality of ideas, as categorized by Shah's terminology (Shah et al., 2003).

In Table 1, the findings were generally unsurprising, aligning with other studies (Agogino et al., 2016), so quotes are left out due to space constraints. However, it was interesting that reframing the problem was valued for sustainability as well as for normal design innovation, so an illustrative quote was included.

Table 1. Why often-mentioned traditional design practices are valued ("IV" = innovation value, "SV" = sustainability value, "OV" = other value)

\begin{tabular}{|l|ll|}
\hline $\begin{array}{l}\text { Traditional Design } \\
\text { Practice }\end{array}$ & Reasons Valued \& Criticized, Illustrative Quotes \\
\hline Human-Centred Design & $\begin{array}{l}\text { OV: Collaboration } \\
\text { (Value of component activities below) }\end{array}$ & CR: (None described) \\
\hline Brainstorming & $\begin{array}{l}\text { IV: Results: quantity of ideas, novelty of } \\
\text { ideas, quality of ideas } \\
\text { OV: Collaboration }\end{array}$ & CR: Vague / superficial results \\
\hline User Needs / Empathy & $\begin{array}{l}\text { IV: Focus / clarify thought } \\
\text { IV: Exploration }\end{array}$ & CR: Time-consuming \\
\hline Research & IV: New lens & CR: (None described) \\
\hline Prototyping & OV: Feedback (enabling user testing) & CR: (None described) \\
\hline User Testing & OV: Feedback & CR: (None described) \\
\hline \multirow{3}{*}{$\begin{array}{l}\text { Defining / Reframing } \\
\text { the Problem }\end{array}$} & $\begin{array}{l}\text { SV, IV: New lens } \\
\text { SV, IV: Problem redefinition }\end{array}$ & $\begin{array}{l}\text { “That's what reframing is, right? Are we really supposed to be designing a better } \\
\text { car here? Or maybe, we should be thinking about transportations at large... So } \\
\text { that reframing thing is right there in design process, but now you're pulling in all } \\
\text { your sustainability context... }\end{array}$ \\
\hline
\end{tabular}

Table 2 shows the types of reasons listed for valuing often-mentioned design practices. Space limitations prevent displaying this level of analysis for all practices in Figure 2. Table 2 shows that every practice is valued for a unique combination of reasons, related to sustainability, innovation, or other value. These values are useful at different phases in the design process, e.g., providing a new lens is primarily useful early when ideating; aiding decision-making is primarily useful later when committing to a design direction; a structured process is useful throughout—as quoted, "they're not just relegated to one specific portion of the design cycle."

For commonalities in sustainability and innovation, the value of providing a new lens provided both sustainability and innovation value for four different design practices (beginning ideas from a point of view of sustainability, rather than beginning ideas from a traditional point of view and rejecting all that fail a sustainability test). Broadening scope and problem redefinition also provided both sustainability and innovation value by "focusing on the right problem". Also note the other design process values like collaboration, inspiration, or providing structure. Finally, while company culture was not mentioned often enough to appear in Table 2, one person suggested it may overwhelm all design practices, quoting Peter Drucker, "culture eats process for lunch." 
Table 2. Why often-mentioned sustainable design practices are valued ("SV"= sustainability value, "IV" = innovation value, "OV" = other value, "CR" = criticism)

\begin{tabular}{|c|c|c|}
\hline $\begin{array}{l}\text { Sustainable Design } \\
\text { Practice }\end{array}$ & $\begin{array}{l}\text { Reasons Valued \& Criticized, } \\
\text { Illustrative Quotes }\end{array}$ & \\
\hline \multirow[b]{2}{*}{$\begin{array}{l}\text { Green Goals / } \\
\text { Strategies }\end{array}$} & \multicolumn{2}{|l|}{$\begin{array}{l}\text { SV: Results (no other benefits } \\
\text { explicitly mentioned; presumably goal- } \\
\text { setting.) }\end{array}$} \\
\hline & \multicolumn{2}{|c|}{$\begin{array}{l}\text { "We'll think about materials and flexibility, and trying to eliminate processes that } \\
\text { use bad materials or ...create parts or assemblies that are not recyclable or that } \\
\text { have poor end-of-use." } \\
\text { "None of that is really innovation, I don't think, those are just best practices to be } \\
\text { sustainable." }\end{array}$} \\
\hline \multirow{2}{*}{$\begin{array}{l}\text { Life-Cycle Assessment } \\
\text { (LCA) }\end{array}$} & $\begin{array}{l}\text { SV: Aids decision-making } \\
\text { SV: Make consequences concrete } \\
\text { OV: "Immersive" focus (Cherry and } \\
\text { Latulipe, 2014) }\end{array}$ & $\begin{array}{l}\text { CR: Difficult } \\
\text { CR: Expensive in time } \\
\text { CR: Can be perfunctory }\end{array}$ \\
\hline & \multicolumn{2}{|c|}{$\begin{array}{l}\text { "Because the client said, 'Oh, wow! I didn't realize that this aspect of the device } \\
\text { was so impactful,' they gave us the green light to start focusing on combining and } \\
\text { simplifying that area." } \\
\text { "In the wrong hands, I think it can be an exercise that's almost just done just to go } \\
\text { through the motions, to say they did an LCA, and then not do anything with it." }\end{array}$} \\
\hline \multirow{2}{*}{$\begin{array}{l}\text { Cradle to Cradle Book } \\
\text { (not certification) } \\
\text { (McDonough and } \\
\text { Braungart, 2002) }\end{array}$} & $\begin{array}{l}\text { SV, IV: New lens } \\
\text { SV: Simplicity }\end{array}$ & CR: Too abstract \\
\hline & $\begin{array}{l}\text { "It's more cut and dried." } \\
\text { "Cradle to Cradle contributes this idea } \\
\text { nutrients from natural nutrients." }\end{array}$ & fupcycling, and separating technical \\
\hline \multirow{2}{*}{$\begin{array}{l}\text { Biomimicry } \\
\text { (Benyus, 1997; } \\
\text { Baumeister et al., 2013) }\end{array}$} & $\begin{array}{l}\text { SV, IV: New lens } \\
\text { SV: Simple idea } \\
\text { OV: Inspiring } \\
\text { OV: Helps consultancies market } \\
\text { themselves to clients }\end{array}$ & $\begin{array}{l}\text { CR: Difficult } \\
\text { CR: Not Actionable } \\
\text { CR: Doesn't Drive Sustainability }\end{array}$ \\
\hline & \multicolumn{2}{|c|}{$\begin{array}{l}\text { "You discover things with Biomimicry, you realize you would have never been in } \\
\text { that neighbourhood without using it." } \\
\text { "I don't agree that biomimicry should be in as part of the sustainability } \\
\text { discussion. ... if I mimic something, but man it's destroyed the environment 'cause } \\
\text { I've got to do this chemical process to get those little gecko foot pads. ...For me } \\
\text { as an engineer, biomimicry is probably the most interesting one just from a } \\
\text { mechanism point of view, or new materials, or new processes point of view." }\end{array}$} \\
\hline \multirow{2}{*}{ Systems Thinking } & $\begin{array}{l}\text { SV, IV: Broadening scope } \\
\text { SV, IV: Problem redefinition } \\
\text { SV, IV: New lens } \\
\text { OV: Collaboration }\end{array}$ & CR: (None described) \\
\hline & \multicolumn{2}{|c|}{$\begin{array}{l}\text { "[it is] very freeing to know... what this could mean in the bigger picture... Are } \\
\text { we focusing on the right problem in terms of addressing the impact of this? Let's } \\
\text { sketch it out, let's make sure that's we've got our sights pointed in the right } \\
\text { direction." }\end{array}$} \\
\hline
\end{tabular}




\begin{tabular}{|c|c|}
\hline & $\begin{array}{l}\text { "I'm not an engineer, but I can sit there with Pepsi and Dole... and talk about... } \\
\text { what this could mean in the bigger picture, and how it works on production, and } \\
\text { that kind of stuff; but without systems thinking methodologies, there's no way I } \\
\text { could do that." }\end{array}$ \\
\hline \multirow{2}{*}{$\begin{array}{l}\text { The Natural Step } \\
\text { (Robèrt, 1991; Baxter et } \\
\text { al., 2009) }\end{array}$} & $\begin{array}{l}\text { SV, IV: New lens } \\
\text { SV: Focus / clarify thought } \\
\text { SV: Envision perfect sustainability } \\
\text { OV: Structured process }\end{array}$ \\
\hline & $\begin{array}{l}\text { "Now that you've actually articulated what it looks like and doesn't, I can actually } \\
\text { see gaps. Because by saying something is sustainable in and of itself, it's almost } \\
\text { meaningless, I don't know what that means. It's a nice idea, but until it's made } \\
\text { more concrete, I can't do anything with it." }\end{array}$ \\
\hline \multirow{2}{*}{$\begin{array}{l}\text { Design Specifications / } \\
\text { Briefs }\end{array}$} & $\begin{array}{ll}\text { SV: Commit teams to sustainability } & \text { CR: Not a common practice } \\
\text { IV: May drive innovation } & \text { CR: May cause client resistance }\end{array}$ \\
\hline & $\begin{array}{l}\text { "To the extent that [sustainability goals] become not optional, they force } \\
\text { innovation." } \\
\text { "They see it as a cost, they don't see it as an opportunity, that was a challenge." }\end{array}$ \\
\hline \multirow{2}{*}{$\begin{array}{l}\text { Green Certifications / } \\
\text { Scorecards: } \\
\text { Cradle to Cradle } \\
\text { Certification } \\
\text { (MBDC, 2012), } \\
\text { EPEAT Certification } \\
\text { (IEEE, 2009), } \\
\text { Wal-Mart Packaging } \\
\text { Sust. Scorecard } \\
\text { (Wal-Mart, 2006), etc. }\end{array}$} & $\begin{array}{l}\text { SV: Drive markets } \\
\text { IV: Product marketability } \\
\text { OV: Align teams }\end{array}$ \\
\hline & $\begin{array}{l}\text { "Gives the user pride in buying... and it comes to a point where they say, okay, I } \\
\text { am willing to pay } \$ 5 \text { more for the iPhone which is platinum certified." } \\
\text { "It's made working with engineers a lot easier, because I can walk in and say, } \\
\text { 'Are you prepped for scoring against the scorecard?' They're like, 'Yeah, yeah, } \\
\text { we're set.". }\end{array}$ \\
\hline \multirow{2}{*}{$\begin{array}{l}\text { Green Design Guides: } \\
\text { Living Principles } \\
\text { (Brink et al., 2009), } \\
\text { Designer's Field Guide } \\
\text { to Sustainability } \\
\text { by Lunar (2008), etc. }\end{array}$} & $\begin{array}{l}\text { SV: Easy yet comprehensive } \\
\text { SV: Focus / clarify thought } \\
\text { OV: Structured process }\end{array}$ \\
\hline & $\begin{array}{l}\text { "They are sort of simple metrics to use to remind the person designing of what } \\
\text { they should be thinking about. So I kind of like it, because they cover a lot of } \\
\text { bases, and they're not just relegated to one specific portion of the design cycle." } \\
\text { "It can actually kind of create entrenched workflows." }\end{array}$ \\
\hline
\end{tabular}

\subsection{Generalizability}

Reliability and generalizability of the 27 interviews were checked against 183 surveys of a different population, as described in Methods, with $1 / 4$ as many sustainability specialist job roles and far fewer designers or engineers with sustainability experience. Counting mentions of design practices showed similarities and differences to interview results, as shown in Table 3. Note that no survey respondents made any critical / negative comments, and almost none answered why they valued practices (survey responses were curt, mostly lists, generally $1 / 10^{\text {th }}-1 / 100^{\text {th }}$ the length of interview responses). Thus, qualitative analyses such as Table 1 and 2 were not practical.

Table 3 shows that Human-Centred Design and its components were often valued by both populations; they were also valued in similar proportions, supporting the notion that interviewees represented the broader population adequately, even if too small for statistics to be meaningful. Table 3 also shows significant differences: sustainable design practices were only mentioned frequently in the population 
with far more sustainability experts, unsurprisingly. This underscores the motivation of this research to bring green design practices to more professionals by showing their value beyond sustainability.

Table 3. Comparison of design practices valued in interviews versus surveys "Often" = five or more mentions for interviews, ten or more mentions for surveys

\begin{tabular}{|c|c|c|}
\hline $\begin{array}{l}\text { Often mentioned in both } \\
\text { interviews and surveys }\end{array}$ & $\begin{array}{l}\text { Often mentioned in } \\
\text { interviews but not surveys }\end{array}$ & $\begin{array}{l}\text { Often mentioned in } \\
\text { surveys but not interviews }\end{array}$ \\
\hline $\begin{array}{l}\text { - Brainstorm } \\
\text { - User Needs / Empathy } \\
\text { - Prototype } \\
\text { - Human-Centred Design } \\
\text { - Design Thinking } \\
\text { - Research } \\
\text { - User test }\end{array}$ & $\begin{array}{l}\text { - (Custom Method / Combination) } \\
\text { - Green Goals / Strategies } \\
\text { - LCA } \\
\text { - Cradle to Cradle Book } \\
\text { - Biomimicry } \\
\text { - Systems Thinking } \\
\text { - Iterate } \\
\text { - The Natural Step } \\
\text { - Green Design Spec / Brief } \\
\text { - Green Certification } \\
\text { - Green Design Guide }\end{array}$ & $\begin{array}{l}\text { - Competitive Analysis } \\
\text { - Sketching / Drawing } \\
\text { - Critique / Design Review }\end{array}$ \\
\hline
\end{tabular}

\subsection{How do designers choose their design practices?}

Participants describing both traditional and sustainable design practices strongly preferred to use not just one design practice, but several. Some said, "I kind of pick and choose, I'm a salad bar," "I'm so often designing on my own that it's all just mixed together and intuitive more than anything else," or "Each designer has their own special tool belt or toolkit that they'd like to carry with them to every project." This was true both for teams and individuals, and it was especially true for sustainable design practice. Respondents also spoke of the importance of combining sustainable design practices with Human Centred Design or other traditional design approaches to ensure product usefulness, practicality, or marketability.

Practitioners combine traditional design practices because their needs vary by time or project ("Everybody sort of has a gut feel for what's the right tool for now," and "Each designer has their own special tool belt or toolkit.") Design consultancies also combined practices due to the bespoke nature of their client work, with interviewees reporting, "Each of our projects tends to be so different that it's not that we have a checklist of, here are the activities that we must do," and "We very much follow a framework, but there's a lot of variability within that framework. So it's not a cookie cutter mould, but we know we're going to make cookies." Sometimes mixing methods was not only for problem solving, but for consultancies marketing their services: "What I value is a combination of what I think will yield an effective and innovative result, and also what I think is likely to get the clients excited and more likely to choose us versus competitive alternatives in the marketplace." In order to make such decisions, practitioners need to know the values of different design practices.

For sustainable design, all the above factors still apply, but with even more specialized design tools providing more specialized value. This leads to more mixing of methods: "Having learned The Natural Step, having learned Cradle to Cradle, [and others] ... none of those frameworks are complete and they all have to be augmented anyway." This was seen not as a problem but as enabling adaptability, as with traditional design methods: "Sustainability is very similar [to traditional design], in the sense that there's a bunch of tools, you don't have to use them all, you can develop your own, mix them if you want, but you need to cover all the bases, which are ecological, financial, social, and cultural issues, and impacts throughout the entire lifecycle." Again, to decide what practices to use for what, practitioners need to know the values of different design practices, as described in Table 2. Choosing practices that provide both sustainability and innovation value should help design teams. 


\section{Limitations}

While these interviews produced valuable insights, this study was limited in several ways. First, there was a small sample size; further studies could interview enough participants to determine statisticallysignificant trends, and recruit participants from more industries in more locations, with a broader demographic distribution. Second, the survey question asking what design practices people value and why produced disappointing results in the respondents' lack of explanations; the question could have been split into two separate questions. Finally, it would be ideal to compare interview results against long-term observations of the interviewees' actual work practices, because self-reporting can be unreliable. Such studies would be time-consuming and thus expensive, but might provide other benefits such as greater chance for experimentation.

\section{Summary and conclusions}

The interviews of designers, engineers, managers, and sustainability specialists showed that they value a wide range of traditional and sustainable design practices - so wide that most practices were only mentioned once or twice, though some were mentioned by many. The design practices valued for both sustainability and innovation were systems thinking, The Natural Step, research, analogy, company culture, Whole System Mapping, and Natural Capitalism / Factor Ten Engineering. Of these, the two that were frequently mentioned were systems thinking and The Natural Step. Results were not statistically significant, due to small sample size, but can aid qualitative interpretation; differences by interviewee demographic were tested for job role, company size, company type, and gender, but no differences were significant.

Interviewees valued different design practices for different reasons, explaining why many respondents valued combining sustainable design practices with both each other and traditional design practices, particularly human-centred design. Some reasons for value drove both sustainability and innovation: providing a new lens, broadening scope, and problem redefinition. These help break out of traditional boxes to enable freer ideation along more effective avenues. In addition, other values emerged: collaboration and structured process. Other work has theorized how sustainable design practices might be combined advantageously (Faludi, 2017), but empirical research is recommended.

Overall, the interviews here should help design professionals make their own mindful choices about what tools, activities, or mindsets to use in their design process. Choosing design practices to drive both sustainability and innovation should increase the business value of sustainable design, and thus help spread design practices that build a healthier, more prosperous, and more just world.

\section{Acknowledgments}

This work was partially funded through US National Science Foundation IGERT grant \#1144885.

\section{References}

Agogino, A.M., Beckman, S.L., Castaños, C., Kramer, J., Roschuni, C. and Yang, M. (2016), "Design Practitioners' Perspectives on Methods for Ideation and Prototyping”, International Journal of Engineering Education, Vol. 32 No. 3, pp. 1428-1437.

Ameli, M., Mansour, S. and Ahmadi-Javid, A. (2017), “A sustainable method for optimizing product design with trade-off between life cycle cost and environmental impact", Environment, Development and Sustainability, Vol. 19 No. 6, pp. 2443-2456. https://doi.org/10.1007/s10668-016-9864-x

Aronson, D. (2013), Sustainability Driven Innovation: Harnessing Sustainability's Ability to Spark Innovation. [online] Deloitte Development LLC. Available at: http://www.greenprof.org/wpcontent/uploads/2013/12/Sustainability_Driven_Innovation_102513.pdf

Baumeister, D., Tocke, R., Dwyer, J., Ritter, S. and Benyus, J. (2013), Biomimicry Resource Handbook: A Seed Bank of Best Practices, Biomimicry 3.8, Missoula, MT, USA.

Baxter, K., Boisvert, A., Lindberg, C. and Mackrael, K. (2009), Sustainability Primer: Step By Natural Step. [online] The Natural Step, Ottawa, Canada. Available at: http://www.thenaturalstep.org/project/sustainabilityprimer-step-by-natural-step (accessed 21.07.2016).

Benyus, J.M. (1997), Biomimicry: Innovation Inspired By Nature, William Morrow, New York. 
Brink, G., Destandau, N. and Hamlett, P. (2009), Genealogy of the Living Principles. [online] AIGA Center for Sustainable Design, New York, Available at: https://carlosfiorentino.files.wordpress.com/2010/03/aiga_the-living-principles.pdf

Ceschin, F. and Gaziulusoy, I. (2016), "Evolution of design for sustainability: From product design to design for system innovations and transitions", Design Studies, Vol. 47, pp. 118-163. https://doi.org/10.1016/j.destud.2016.09.002

Cherry, E. and Latulipe, C. (2014), "Quantifying the creativity support of digital tools through the creativity support index", ACM Transactions on Computer-Human Interaction, Vol. 21 No. 4. https://doi.org/10.1145/2617588

Crul, M.R.M. and Diehl, J.C. (2006), Design for Sustainability: A Practical Approach for Developing Economies, United Nations Environment Program (UNEP) - Earthprint \& Delft University of Technology (TU Delft), Paris, Delft.

Epstein, M.J. and Buhovac, A.R. (2014), Making Sustainability Work: Best Practices in Managing and Measuring Corporate Social, Environmental, and Economic Impacts, Berrett-Koehler Publishers Inc., San Francisco, USA.

Faludi, J. (2017), "Recommending Sustainable Design Methods and Combinations by Characterizing Activities and Mindsets", International Journal of Sustainable Design (accepted for publication 2017).

Griffin, A. and Hauser, J.R. (1993), “The Voice of the Customer”, Marketing Science, Vol. 12 No. 1, pp. 1-27. https://doi.org/10.1287/mksc.12.1.1

Hawken, P., Lovins, A.B. and Lovins, L.H. (2013), Natural Capitalism: The next Industrial Revolution, Back Bay Books, Boston.

IEEE (2009), Electronic Product Environmental Assessment Tool (EPEAT), IEEE 1680-2009 Standard for Environmental Assessment of Electronic Products, Green Electronics Council.

Kobayashi, H. (2006), "A systematic approach to eco-innovative product design based on life cycle planning", Advanced Engineering Informatics, Vol. 20 No. 2, pp. 113-125. https://doi.org/10.1016/j.aei.2005.11.002

Lindahl, M. (2006), "Engineering designers' experience of design for environment methods and tools Requirement definitions from an interview study", Journal of Cleaner Production, Vol. 14 No. 5, pp. 487496. https://doi.org/10.1016/j.jclepro.2005.02.003

Lozano, R. (2015), “A Holistic Perspective on Corporate Sustainability Drivers", Corporate Social Responsibility and Environmental Management, Vol. 22 No. 1, pp. 32-44. https://doi.org/10.1002/csr.1325

LUNAR (2008), The Designer's Field Guide to Sustainability. [online] LUNAR Design, San Francisco, Chicago, Singapore. Available at: http://www.lunar.com/docs/the_designers_field_guide_to_sustainability_v1.pdf (accessed 30.06.2016).

MBDC (2012), Overview of the Cradle to Cradle Certified Product Standard, Version 3.0. [online] McDonough Braungart Design Chemistry, LCC Available at: https://www.c2ccertified.org/images/uploads/C2CCertified_V3_Overview_121113.pdf_ (accessed 21.06.2016).

McDonough, W. and Braungart, M. (2002), Cradle to Cradle: Remaking the Way We Make Things, North Point Press, New York, USA.

Oehlberg, L., Bayley, C., Hartman, C. and Agogino, A. (2012), "Mapping the Life Cycle Analysis and Sustainability Impact of Design for Environment Principles", Proceedings of the 19th CIRP Conference on Life Cycle Engineering, Berkeley, CA USA, May 23-25, 2012, Springer, Berlin, Heidelberg, pp. 221-226. https://doi.org/10.1007/978-3-642-29069-5 38

Papanek, V. (1995), The Green Imperative: Natural Design for the Real World, Thames and Hudson, New York, USA.

Porter, M.E. and Kramer, M.R. (2011), "Creating shared value”, Harvard Business Review, Vol. 89 No. 1/2, pp. $62-77$.

Robèrt, K.-H. (1991), "Educating A Nation: The Natural Step”, In Context - A Quarterly of Humane Sustainable Culture, Vol. 28, pp. 10-15.

Rossi, M., Germani, M. and Zamagni, A. (2016), "Review of ecodesign methods and tools. Barriers and strategies for an effective implementation in industrial companies", Journal of Cleaner Production, Vol. 129, pp. 361373. https://doi.org/10.1016/j.jclepro.2016.04.051

Santolaria, M., Oliver-Solà, J., Gasol, C.M., Morales-Pinzón, T. and Rieradevall, J. (2011), "Eco-design in innovation driven companies: perception, predictions and the main drivers of integration. The Spanish example", Journal of Cleaner Production, Vol. 19 No. 12, pp. 1315-1323. https://doi.org/10.1016/j.jclepro.2011.03.009

Shah, J.J., Smith, S.M. and Vargas-Hernandez, N. (2003), "Metrics for measuring ideation effectiveness", Design Studies, Vol. 24 No. 2, pp. 111-134. https://doi.org/10.1016/S0142-694X(02)00034-0 
Telenko, C., O’Rourke, J.M., Seepersad, C.C. and Webber, M.E. (2016), “A compilation of design for environment guidelines", Journal of Mechanical Design, Vol. 138 No. 3, pp. 031102. https://doi.org/10.1115/1.4032095

Van Hemel, C. and Cramer, J. (2002), "Barriers and stimuli for ecodesign in SMEs", Journal of Cleaner Production, Vol. 10 No. 5, pp. 439-453. https://doi.org/10.1016/S0959-6526(02)00013-6

Wal-Mart (2006), Wal-Mart Unveils 'Packaging Scorecard' to Suppliers. [online] Walmart Inc. Available at: http://corporate.walmart.com/_news_/news-archive/2006/11/01/wal-mart-unveils-packaging-scorecard-tosuppliers (accessed 28.06.2017).

Dr. Jeremy James Faludi, Assistant Professor

Dartmouth College, Engineering

14 Engineering Drive, 03755 Hanover, United States

Email: faludi@dartmouth.edu 